\title{
Effects of esculin and esculetin on the survival of Escherichia coli 0157 in human faecal slurries, continuous-flow simulations of the rumen and colon and in calves
}

\author{
Sylvia H. Duncan ${ }^{1 \star}$, E. Carol McWilliam Leitch ${ }^{1}$, Karen N. Stanley ${ }^{1}$, Anthony J. Richardson ${ }^{1}$, \\ Richard A. Laven ${ }^{2}$, Harry J. Flint ${ }^{1}$ and Colin S. Stewart ${ }^{1}$ \\ ${ }^{1}$ Gut Microbiology and Immunology Division, Rowett Research Institute, Bucksburn, Aberdeen AB21 $9 S B$, UK \\ ${ }^{2}$ Scottish Agricultural College, St Mary's Industrial Estate, Dumfries DG1 1DX, UK
}

(Received 21 May 2003 - Revised 1 December 2003 - Accepted 16 January 2004)

\begin{abstract}
The human pathogen Escherichia coli O157:H7 is thought to be spread by direct or indirect contact with infected animal or human faeces. The present study investigated the effects of the plant coumarin esculin and its aglycone esculetin on the survival of a strain of $E$. coli O157 under gut conditions. The addition of these compounds to human faecal slurries and in vitro continuous-flow fermenter models simulating conditions in the human colon and rumen caused marked decreases in the survival of an introduced strain of E. coli O157. When four calves were experimentally infected with E. coli $\mathrm{O} 157$ and fed esculin, the pathogen was detected in five of twenty-eight (18\%) of faecal samples examined post-inoculation, compared with thirteen of thirty-five $(37 \%)$ of faecal samples examined from five control calves not fed esculin. Coumarin compounds that occur naturally in dietary plants or when supplemented in the diet probably inhibit the survival of E. coli $\mathrm{O} 157$ in the gut.
\end{abstract}

Plant coumarins: Escherichia coli O157: Rumen: Colon

Escherichia coli $\mathrm{O} 157: \mathrm{H7}$ has emerged as a serious foodborne pathogen in the UK and other developed countries over the past 20 years. Human infection can result from the ingestion of as few as 100 viable bacterial cells (Griffin \& Tauxe, 1991) and commonly results in bloody diarrhoea and haemorrhagic colitis. Potentially fatal extra-intestinal complications may occur, particularly in the young and the elderly, resulting in haemolytic uraemic syndrome and thrombolytic thrombocytopenic purpurea (Griffin \& Tauxe, 1991). The gut of herbivorous ruminant animals such as cattle and sheep is the main reservoir of $E$. coli O157 and transmission to man occurs principally through contamination of the food chain, or of the environment, by faeces from infected animals (Kudva et al. 1998). Except in neonates (Dean-Nystrom et al. 1998), carrier animals usually do not show outward evidence of disease. Faeco-oral transmission is also a significant factor in the spread of this pathogen in human populations. From studies in Wales, Parry \& Salmon (1998) calculated a household transmission rate of about $7 \%$.

Antibiotic therapy of $E$. coli $\mathrm{O} 157$ infection is controversial since it has been associated with an increased risk of haemolytic-uraemic syndrome (Wong et al. 2000) and, in some instances, appears to increase the risk of secondary infection (Neill, 1998). Furthermore, the use of antibiotics as growth promoters in animal husbandry is accompanied by an unacceptable risk of enhancing the spread of resistance genes (Flint et al. 1987; Barbosa \& Levy, 2000; Shoemaker et al. 2001). Alternative approaches for controlling the shedding of E. coli $\mathrm{O} 157$ in sheep and cattle include the use of probiotics (Zhao et al. 1998) and dietary manipulation, for example, decreasing the amount of cereal grains fed to animals (Diez-Gonzalez et al. 1998). Plant coumarins are known to inhibit the growth of E. coli O157 (Duncan et al. 1998). These plant metabolites are found in grassland herbage and may occur commonly in the free state and as glycosides (Murray et al. 1982). Duncan et al. (1998) showed that coumarin inhibited the growth of E. coli $\mathrm{O} 157$ in pure culture and in batch-culture incubations of rumen contents. Under the conditions used, the coumarins had relatively minor effects on the predominant anaerobic faecal microflora.

The fermentative compartments of the gut, including the rumen and colon of sheep and cattle and the human colon, are populated predominantly by anaerobes which produce SCFA, carbon dioxide, methane and water by fermentation (Hungate, 1966). The population density of anaerobic bacteria ranges from about $10^{8}$ to $10^{11}$ viable cells $/ \mathrm{ml}$ depending on the gut site, the nature of the diet and the time elapsed after the ingestion of food (Wolin, 1981; Wilson, 1997; Russell \& Rychlik, 2001). E. coli and other facultative bacteria normally comprise between 0.01 and $1 \%$ of 
the total bacterial population of the gut (Hungate, 1966; Wilson, 1997). E. coli O157 colonises the rumen and colon of naturally infected ruminants. In cattle at slaughter at abattoirs in England, the incidence of E. coli O157 and the numbers of commensal $E$. coli were higher in the colon than in the rumen (Laven et al. 2003). Nonetheless it is clear that, following ingestion, E. coli 0157 must pass though the rumen and the other gut compartments before colonising the lower gastrointestinal tract. Control measures aimed at reducing the survival of E. coli $\mathrm{O} 157$ in the rumen and colon may be useful in ultimately reducing shedding rates amongst animals.

Here we report the effects of the plant coumarin esculin and its aglycone esculetin on the survival of E. coli $\mathrm{O} 157$ in human faecal slurries, fermenter models simulating conditions in the human colon and in the rumen, and the effect on faecal shedding following the experimental infection of calves.

\section{Materials and methods}

Escherichia coli strains, growth conditions, inocula preparation and tracking

E. coli serogroup O157 (NCTC 12900) used in the present study (12900) does not carry verocytotoxin genes or an inducible lambdoid prophage (James et al. 2001). Thus the laboratory and animals studies such as those described in the present paper can be performed at Health and Safety Executive category 2 instead of category 3 level of containment. Access to the latter facilities is limited in the UK, reducing the opportunity for relevant investigations. Cultures were routinely grown in Luria Bertani (LB) broths (Sambrook et al. 1982) (5 ml) in glass Hungate tubes (Bellco Glass Inc., Vineland, NJ, USA). E. coli O157 (12900) was grown for the inoculation of the colon-simulating fermenter in $100 \mathrm{ml}$ volumes of LB medium at $37^{\circ} \mathrm{C}$ for $18 \mathrm{~h}$ in a shaking incubator $(150 \mathrm{rpm})$. Cultures were centrifuged at $2500 \mathrm{~g}$ for $15 \mathrm{~min}$ and washed in sterile anaerobic phosphate buffer (APB; $50 \mathrm{~mm}$ ) containing $0.5 \%(\mathrm{w} / \mathrm{v})$ cysteine $\mathrm{HCl}$ as a reducing agent and prepared under $\mathrm{O}_{2}$-free $\mathrm{CO}_{2}$. Pelleted cells were re-suspended in $10 \mathrm{ml} \mathrm{APB}$ and inoculated through a port into the fermenter vessel, then washed through with a further $10 \mathrm{ml}$ sterile buffer.

For inoculation of the rumen fermenters, frozen stock solutions of E. coli O157 (12900) were inoculated anaerobically into $10 \mathrm{ml}$ broths of M2GSC medium (Miyazaki et al. 1997) and incubated for $24 \mathrm{~h}$ in an orbital shaking incubator $\left(100 \mathrm{rpm}, 37 \pm 1^{\circ} \mathrm{C}\right)$. A sample of $500 \mu \mathrm{l}$ of the culture was used to inoculate the rumen fermenters. The culture was inoculated through a port into the fermenter vessel.

For the experiments with calves, a rifampicin-resistant mutant of E. coli O157 (12900) was created by sub-culturing the strain in increasing concentrations of rifampicin. Single colonies were tested for growth in broth medium containing either 75 or $100 \mu \mathrm{g}$ rifampicin $/ \mathrm{ml}$. The E. coli O157 rifampicin-resistant mutant $\left(12900^{\mathrm{R}}\right)$ was maintained on LB agar plates containing $75 \mu \mathrm{g}$ rifampicin $/ \mathrm{ml}$.

\section{Selective counting of bacterial groups}

Anaerobic, facultative anaerobic and faecal coliform bacteria were enumerated during E. coli 0157 survival experiments. Decimal serial dilutions of samples were prepared in $9 \mathrm{ml}$ anaerobic diluting fluid or $900 \mu \mathrm{l}$ PBS. Total anaerobic bacteria were enumerated on roll tubes (Bryant, 1972) of M2GSC medium containing $2.0 \%(\mathrm{w} / \mathrm{v})$ agar. Total facultative counts were made on Nutrient agar (Oxoid, Basingstoke, Hants, UK). The total coliforms were enumerated on MacConkey agar. E. coli $\mathrm{O} 157$ cells were enumerated on sorbitol MacConkey agar supplemented with cefixime tellurite (CT-SMAC; Oxoid, Basingstoke, Hants, UK) as described by Chapman \& Siddons (1996) or on Rainbow agar (Biolog Inc., Hayward, CA, USA). Roll tubes were incubated for $72 \mathrm{~h}$ and the plates for $48 \mathrm{~h}$ at $38^{\circ} \mathrm{C}$.

Effect of esculin and esculetin on survival of Escherichia coli $O 157$ on incubation with human faeces

A faecal slurry (10\% (w/v) final concentration) was prepared by suspending freshly voided faeces from a healthy vegetarian adult male (50 years old) in anaerobic $50 \mathrm{~mm}-$ APB. Hungate culture tubes containing $10 \%$ faecal slurry $(9.75 \mathrm{ml})$ were inoculated with $100 \mu \mathrm{l} \mathrm{E}$. coli $\mathrm{O} 157$ (12900) that had been incubated for $18 \mathrm{~h}$ at $38^{\circ} \mathrm{C}$ and then incubated at $38^{\circ} \mathrm{C}$ under $\mathrm{O}_{2}$-free $\mathrm{CO}_{2}$. Sub-samples $(100 \mu \mathrm{l})$ were removed for enumeration at intervals as recorded later (p. 751). Esculin and esculetin were prepared as $1 \mathrm{M}$ stock solutions in $80 \%(\mathrm{v} / \mathrm{v})$ dimethyl sulfoxide (DMSO) and appropriate levels were added to give final concentrations of $5 \mathrm{~mm}$. The appropriate levels of DMSO were added to the control tubes. The incubations were conducted as three replicates for each treatment and counts were the average of three replicates at $24 \mathrm{~h}$ intervals for a period of $72 \mathrm{~h}$.

Effect of esculetin on survival of Escherichia coli $O 157$ in a simulation of human colonic fermentation

A continuous-flow single-stage fermenter based on the system of Macfarlane et al. (1989) was used to model human colonic fermentation. The working volume was $900 \mathrm{ml}$, the temperature was maintained at $37^{\circ} \mathrm{C}$ and the $\mathrm{pH}$ was maintained between 6.5 and $6 \cdot 8$. Anaerobiosis was maintained by means of a stream of $\mathrm{O}_{2}$-free $\mathrm{CO}_{2}$ into the head of the medium vessel, and $\mathrm{N}_{2}$ into the fermenter vessel as described by Scott et al. (1998). The medium used contained xylan, amylopectin, arabinogalactan, pectin, potato starch, peptone water (Unipath, Basingstoke, Hants, UK), and haemin, bile salts and minerals (Macfarlane et al. 1989) with (per litre) $3.0 \mathrm{~g} \mathrm{NaHCO} 3,0.5 \mathrm{~g}$ cysteine $\mathrm{HCl}$ and $0.5 \mathrm{ml}$ antifoam A (Sigma, Poole, Dorset, UK). The medium turnover rate for the fermenter vessel was $1 /$ $\mathrm{d}$, corresponding to a dilution rate of $0 \cdot 042 / \mathrm{h}$. The vessel was inoculated with a faecal suspension of $10 \mathrm{~g}$ freshly voided faeces, from a healthy adult male, suspended in $50 \mathrm{~mm}$-APB $(40 \mathrm{ml})$. Esculetin in $80 \%(\mathrm{v} / \mathrm{v})$ DMSO was added to the test vessel and the feed flask to give a final concentration of $10 \mathrm{~mm}$-esculetin and $1.6 \%(\mathrm{v} / \mathrm{v})$ DMSO. 
DMSO only was added to the control vessel and feed flask to give the same final concentration.

\section{Rumen fermenter simulations}

Rumen-simulating fermenters were set up using an apparatus similar to that of Teather \& Sauer (1988), but with a reduced working volume of $550 \mathrm{ml}$. Inoculum was prepared from the rumen contents from three cannulated sheep fed a general-purpose diet (McKain et al. 1992). The rumen contents were pooled, diluted 1:1 with artificial saliva (McDougall, 1948) and $550 \mathrm{ml}$ was added to duplicate fermenters. The general-purpose diet $(5 \mathrm{~g})$, which had been ground to pass through a $1 \mathrm{~mm}$ dry mesh, was added to the fermenter vessel once daily for the first $3 \mathrm{~d}$ and thereafter twice daily. The turnover rate of the fermenter contents was approximately $1.5 / \mathrm{d}$.

E. coli O157 (12900) was added to the fermenter contents to give $3.5 \times 10^{4}$ colony-forming units $(\mathrm{cfu}) / \mathrm{ml}$. Esculin in $80 \%(\mathrm{v} / \mathrm{v})$ DMSO was prepared as for the human colonic fermenter and was added to the test vessel on the fourth day. Viable counts were performed as described earlier (p. 750) to determine the population of total anaerobes, total facultative anaerobes and total coliforms. E. coli $\mathrm{O} 157$ cells were enumerated using Rainbow agar. The fermenters were maintained for $7 \mathrm{~d}(4 \mathrm{~d}$ of testing) and the experiment was repeated using the rumen contents from the same sheep.

Effect of feeding esculin on faecal shedding of Escherichia coli $O 157$ in experimentally infected calves

Friesian-Holstein male calves, 3-4 months of age, were randomly allocated to two treatment groups. The calves were housed indoors in individual pens on concrete floors bedded with wood shavings that were cleaned out daily. A proprietary calf mix was fed twice daily, with the addition of $50 \mathrm{~g}$ esculin sprinkled on the diet in the case of the esculin-treated group.

Before the experiment began, the palatability of esculin was confirmed by feeding a calf $50 \mathrm{~g}$ esculin powder in $20 \mathrm{~kg}$ feed. Animals to be included in the experiment were first confirmed negative for the faecal excretion of E. coli $\mathrm{O} 157$ and rifampicin-resistant E. coli. On days 1 and 2 all ten calves were administered $10 \mathrm{ml}$ of overnight LB culture containing approximately $1 \times 10^{9} \mathrm{cfu}$ of the rifampicin resistant E. coli O157 (strain $12900^{\mathrm{R}}$ )/ml. Five of these animals received esculin in their normal feed on days 1 to 5 inclusively. One of the animals in the group receiving esculin was found to have an unrelated gut malfunction and, as a result, was withdrawn from the experiment. Fresh faecal samples were collected in the morning and transported to the laboratory in chilled containers within $24 \mathrm{~h}$. E. coli O157 $\left(12900^{\mathrm{R}}\right)$ cells were enumerated on MacConkey agar containing $50 \mu \mathrm{g}$ rifampi$\mathrm{cin} / \mathrm{ml}$. Representative rifampicin-resistant colonies were sub-cultured onto MacConkey sorbitol agar and tested with E. coli O157 latex test kit (Oxoid, Basingstoke, Hants, UK) to confirm that they were E. coli 0157 and not spontaneous $E$. coli rifampicin-resistant mutants.

\section{Short-chain fatty acid analysis by gas chromatography}

SCFA were analysed as described by Richardson et al. (1989), except that the derivatisation conditions were modified so that $800 \mu l$ diethyl ether extract was treated with $100 \mu \mathrm{N} N$-methyl- $N$-t-butyldimethylsilyltrifluoroacetimide.

\section{Results}

Batch incubations with human faeces in vitro

Anaerobic batch cultures of $10 \%$ (w/v) human faecal slurry (final concentration), inoculated with E. coli $\mathrm{O} 157$ with or without the addition of esculin or esculetin, were assessed for the survival of total anaerobes, total coliforms and $E$. coli O157. The numbers of coliforms fell by approximately 10 -fold in the controls but by more than 1 000-fold in the presence of the plant metabolites (Fig. 1 (a)). Most significantly, the numbers of E. coli 0157 cells fell sharply in the presence of the plant metabolites. After $72 \mathrm{~h}$ incubation there was a decrease of over 1000fold in the numbers of $E$. coli $\mathrm{O} 157$ cells compared with the control incubations and a decrease of more than 10000 -fold compared with the initial count (Fig. 1 (b)).

During $72 \mathrm{~h}$ incubation, the number of anaerobes fell by about $50 \%$ in the controls, $75 \%$ in the presence of
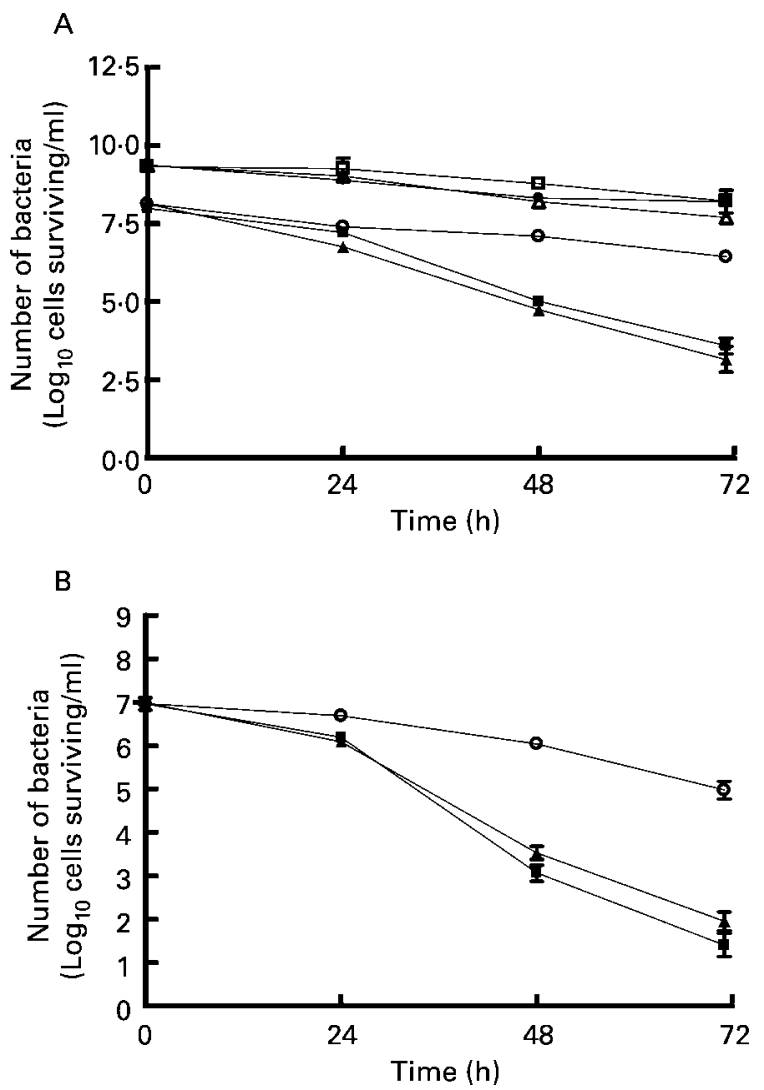

Fig. 1. (A) Effects of esculin and esculetin on the survival of anaerobic bacteria and total coliforms. ( $\square$ ), Anaerobes, control; (๑), anaerobes with esculetin; $(\triangle)$, anaerobes with esculin; $(O)$, coliforms, control; (ם), coliforms with esuletin; $(\boldsymbol{\Delta})$, coliforms with esculin. (B) Escherichia coli 0157 in human faecal slurry in batch culture compared with controls with no added plant metabolites. $(\bigcirc)$, Control; $(\boldsymbol{\Delta})$, esculetin; $(\boldsymbol{\square})$, esculin. Mean values are shown with their standard deviations represented by vertical bars. 
esculetin, and $90 \%$ in the presence of esculin (Fig. 1 (a)). The total SCFA concentrations at the end of the incubations for the control, esculetin- and esculin-containing batch cultures were (n 3): 43.0 (SD 5.1), 39.5 (SD 0.5) and 55.85 (SD 0.7) $\mathrm{mm}$ respectively. The final $\mathrm{pH}$ values of these incubations were 6.35 (SD 0.05) (control), 6.37 (SD 0.02) (esculetin) and 6.21 (SD 0.01) (esculin).

\section{Human colon-simulating fermenters}

A model system designed to simulate human colonic fermentation $\left(37^{\circ} \mathrm{C}, \mathrm{pH} 6 \cdot 5\right.$, dilution rate $\left.0 \cdot 04 / \mathrm{h}\right)$ was used to study the effect of esculetin on the survival of $E$. coli O157 in the presence of human faecal bacteria in continuous culture.

In experiment $1, E$. coli $\mathrm{O} 157$ was introduced on day 7 and esculetin (10 mM) was added on day 21 (Fig. 2). Between days 11 and 21, before the addition of esculetin, the average number of $E$. coli 0157 present was 6.5 (SD $0.5) \times 10^{3} \mathrm{cfu} / \mathrm{ml}(n \mathrm{10})$. Following the addition of esculetin the numbers of $E$. coli $\mathrm{O} 157$ dropped to about 4.4 (SD $1.6) \times 10^{1} \mathrm{cfu} / \mathrm{ml}(n 5)$ between days 26 and 31. Application of the $t$ test showed that the population of $E$. coli in the control period (days 11 to 21 ) differed significantly from that during the esculetin-feeding period (26 to $31 \mathrm{~d}$ ) $(P<0.001)$. When E. coli $\mathrm{O} 157$ was re-introduced in the presence of esculetin on day 31 , its numbers fell sharply to below $10^{2} \mathrm{cfu} / \mathrm{ml}$ by day 38 (Fig. 3). There was no evidence of an effect of esculetin on the numbers of anaerobic bacteria or of total coliforms (Fig. 2).

The results of a second experiment, in which test and control fermenters were run simultaneously with and without esculetin in the medium, are shown in Fig. 3. The reduction in the number of $E$. coli $\mathrm{O} 157$ in the fermenter treated with esculetin was significantly greater than that in the control vessel. Linear regression analysis (Genstat; Lawes Agricultural Trust, Harpenden, Herts, UK) was used to determine the survival of $E$. coli $\mathrm{O} 157$ in the control fermenter compared with the esculetin-fed fermenter.

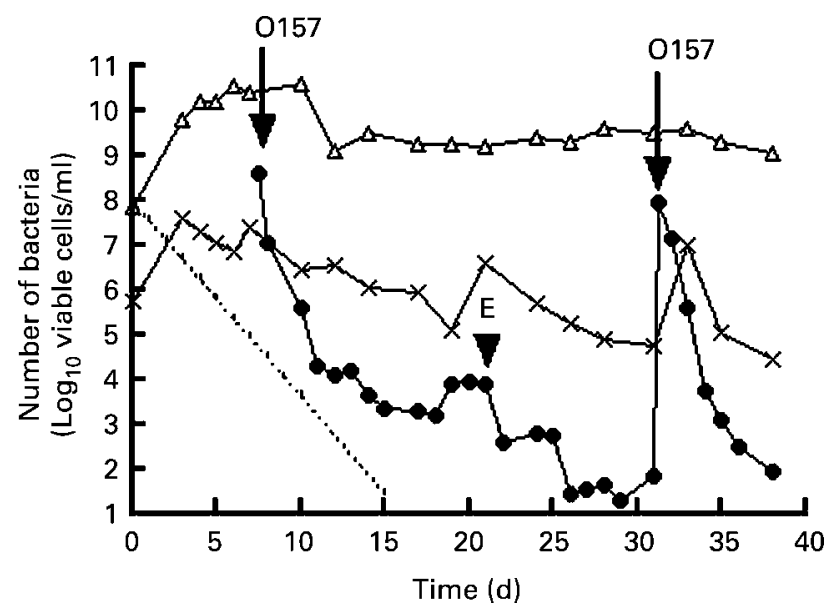

Fig. 2. Numbers of anaerobic bacteria $(\triangle)$, total coliforms $(x)$ and Escherichia coli $\mathrm{O} 157(\bullet)$ in a continuous-flow fermenter simulating human colonic fermentation. Mixed human faecal bacteria were introduced on day 0 , and $E$. coli $\mathrm{O} 157$ on days 7 and 31 . Esculetin ( $E$; final concentration $10 \mathrm{~mm}$ ) was added to the fermenter contents and the medium on day $21 .(\cdots)$, Washout rate.

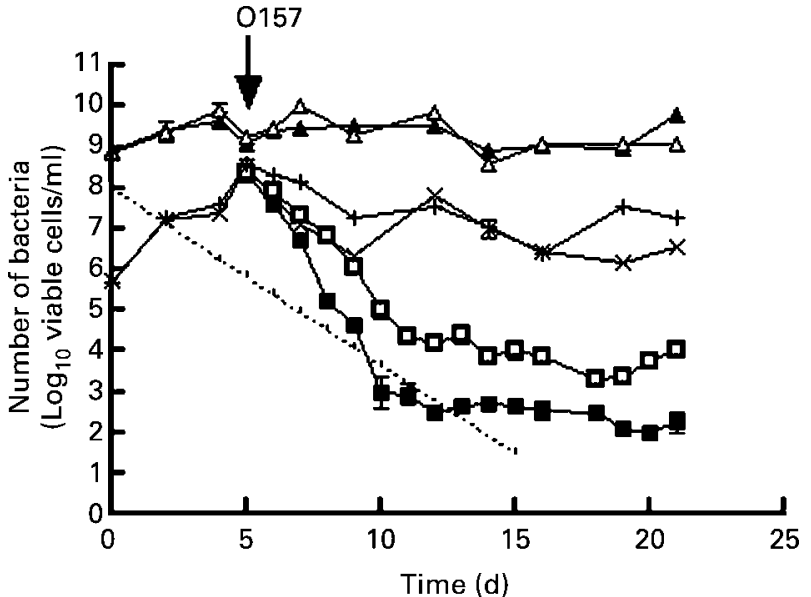

Fig. 3. Numbers of bacteria in a continuous-flow fermenter simulating human colonic fermentation. Mixed human faecal bacteria were introduced on day 0; Escherichia coli 0157 on day 5. Fermenter 1 contained a control medium; fermenter 2 contained the medium plus $10 \mathrm{~mm}$-esculetin. $(\triangle)$, Anaerobic bacteria in fermenter $1 ;(\boldsymbol{\Delta})$, anaerobic bacteria in fermenter $2 ;(+)$, total coliforms in fermenter $1 ;(\times)$, total coliforms in fermenter $2 ;(\square)$, E. coli O157 in fermenter $1 ;(\square)$, E. coli 0157 in fermenter $2 ;(\cdots)$, washout rate.

ANOVA over time was used to compare the decline in numbers of $E$. coli O157 (12900) between the control and treatment vessels and this gave a value of $P=0.004$. As in the previous experiment shown in Fig. 3, esculetin did not appear to affect the total numbers of anaerobes and coliforms. The mean concentration of SCFA in representative samples taken during the study was 56.9 (SD 4.6) $\mathrm{mM}$ ( $n$ 15); adding esculetin to the medium did not significantly change SCFA formation (average 59.2 (SD 5.4) mM; $n$ 15). The molar proportions of the three major SCFA acetate, propionate and butyrate averaged about 4:2:1 throughout the study and were not significantly affected by the presence of esculetin (data not shown).

\section{Rumen-simulating fermenter}

E. coli $\mathrm{O} 157$ (12900) was added to duplicate rumen fermenter vessels and allowed to stabilise for $4 \mathrm{~d}$ before the addition of esculin to one vessel. The initial inoculum of E. coli $\mathrm{O} 157$ was $3.5 \times 10^{4} \mathrm{cfu} / \mathrm{ml}$ but the number increased in the first $4 \mathrm{~d}$ to an average of $1.2 \times 10^{6} \mathrm{cfu} /$ $\mathrm{ml}$. This number was maintained for the remainder of the experiment in the control vessels but, in the test vessels, the number of $E$. coli O157 (12900) decreased after the addition of esculin to a minimum of $4.8 \times 10^{1} \mathrm{cfu} / \mathrm{ml}$ by day 6 (Fig. 4).

In the test vessels, the numbers of anaerobic bacteria increased for the first $2 \mathrm{~d}$ following the addition of esculin compared with the control (days 4 and 5) to $7.4 \times 10^{9} \mathrm{cfu} /$ $\mathrm{ml}$ and thereafter declined slightly for the remainder of the experiment. The total number of coliforms in the test and control vessels was similar throughout (data not shown).

The initial SCFA concentrations in both fermenter vessels decreased slightly from $45 \mathrm{~mm}$ over the first $4 \mathrm{~d}$ during stabilisation. Following the addition of esculin, the total SCFA concentration in the test vessel increased to approximately $50 \mathrm{~mm}$, a level greater than that in the 


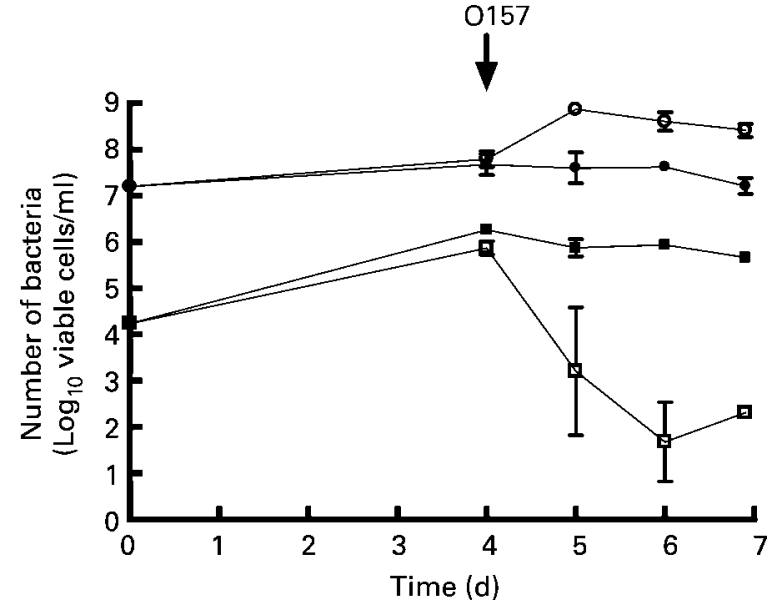

Fig. 4. Numbers of anaerobes and Escherichia coli 0157 in rumen fermenters with and without the addition of esculin ( $\downarrow$; day 4$)$. $(\bullet)$, Total anaerobes without esculin; $(O)$, total anaerobes with esculin;

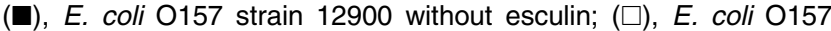
strain 12900 with esculin. Mean values are shown, with standard deviations represented by vertical bars.

control fermenter over the same period of time (data not shown). As expected, acetic acid was the major SCFA followed by propionic acid, then butyric acid.

\section{Calf feeding trial}

Before the experiment began it was demonstrated that calves accepted esculin when it was mixed throughout their solid feed at a concentration of $0.8 \mathrm{~g}$ esculin $/ \mathrm{kg}$ feed. Throughout the experiment no deleterious effect on the health of the animals was observed. None of the animals were excreting E. coli $\mathrm{O} 157$ or rifampicin-resistant $E$. coli. In the $8 \mathrm{~d}$ following the first administration, $E$. coli $\mathrm{O} 157\left(12900^{\mathrm{R}}\right)$ was detected in $37 \%$ of faecal samples from the control group compared with $20 \%$ of samples from the esculin-fed group. The faecal excretion of $E$. coli (total coliform count including all serogroups) was highest on days 2 and 3 (data not shown). E. coli $\mathrm{O} 157$ $\left(12900^{\mathrm{R}}\right)$ was excreted by all five animals in the control group on day 3 compared with two out of four of the esculin-fed group, although the number of E. coli $\mathrm{O} 157$ $\left(12900^{\mathrm{R}}\right)$ in positive samples was similar in both groups. One animal in the control group continued to excrete low levels of E. coli $\mathrm{O} 157\left(12900^{\mathrm{R}}\right)$ up until day 9.

\section{Discussion}

In both the rumen and human colonic ecosystems the predominant bacteria belong to the low $\mathrm{G}+\mathrm{C}$ Gram-positive phylum, including many members of clostridial groups, accompanied by Bacteroides and Prevotella species of the Cytophaga-Flexibacter-Bacteroides phylum of Gram-negative bacteria (Franks et al. 1998; Suau et al. 1999; Tajima et al. 1999; Ramsak et al. 2000; Pryde et al. 2002). The ability to hydrolyse esculin to the aglycone esculetin is a common feature of many of these organisms that possess $\beta$-glucosidase activities (Duncan, 2001).

The recognition of the role of farm animals as a potential reservoir of E. coli O157 (Rasmussen et al. 1993) has focused attention on how the survival of $E$. coli in the gastrointestinal tract might be influenced by the diet. E. coli is known to be sensitive to SCFA produced in fermentative gut compartments such as the rumen and colon (Wolin, 1969; Wallace et al. 1989). Diez-Gonzalez et al. (1998) hypothesised that the differences seen in the shedding of E. coli $\mathrm{O} 157$ by ruminants fed hay or grain might result from differences in the amounts of SCFA produced in the gut. It was argued that when grain is fed, E. coli strains in the rumen, including $E$. coli $\mathrm{O} 157$, become acid habituated, increasing survival during passage through the acid secretions of the ruminant stomach. Duncan et al. (1998) found that SCFA and plant coumarins showed additive effects in the inhibition of growth of E. coli O157. Thus, feeding diets rich in such plant secondary compounds might reduce the population size of E. coli $\mathrm{O} 157$ in the rumen and colon, where SCFA concentrations are high.

Naturally derived plant compounds provide a potentially simple and acceptable way to control the incidence and spread of E. coli $\mathrm{O} 157$ within farm animals. Whilst the potential for the expression of antimicrobial activity by plant secondary compounds in ruminant feeds is well documented (Van Soest, 1994), much of this work has concerned effects on the indigenous populations of anaerobes that inhabit the ruminant gastrointestinal tract. It is recognised that this microbial community is influenced by a range of plant secondary compounds, including tannins, saponins (Wallace et al. 1994), phenolic acids (Chesson et al. 1982), essential oils (Nagy \& Tengerdy, 1968), alkaloids and coumarins (Moniello et al. 1996). The screening of plants or their compounds for antibacterial effects on

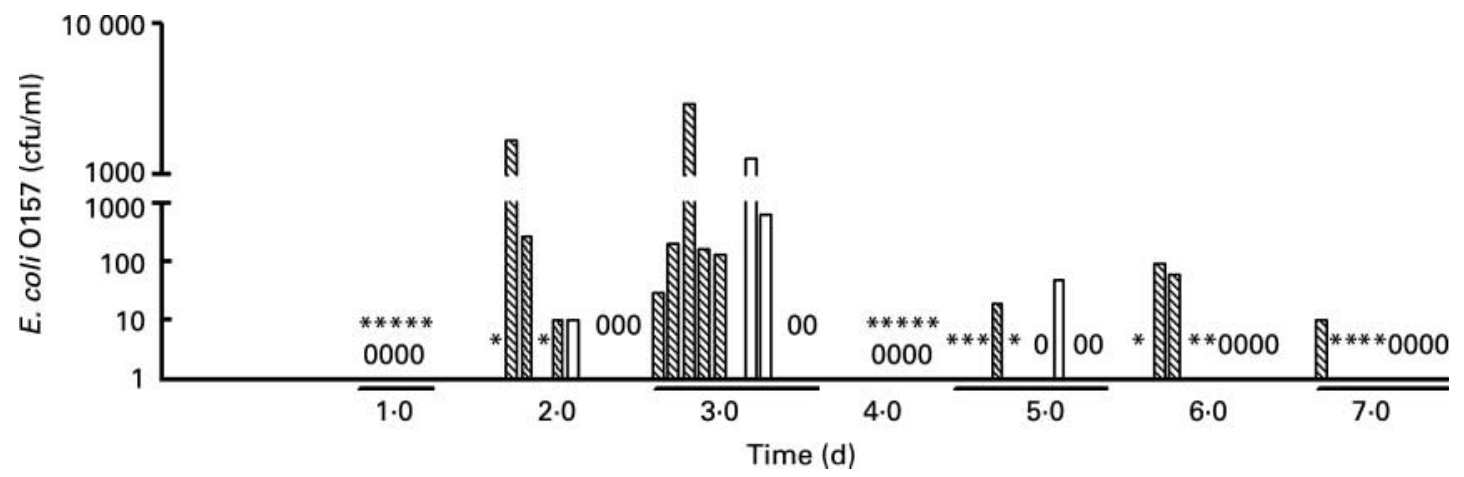

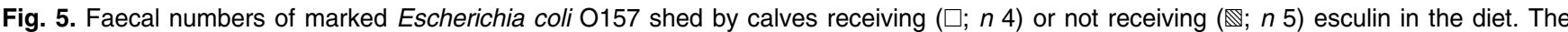
bars represent control calves 1 to 5 and esculin-fed calves 1 to 4 from left to right respectively. $\left({ }^{\star}\right)$, Sample from the control calf group with no E. coli $\mathrm{O} 157$ detected; (0), sample from esculin-fed calf group with no E. coli 0157 detected; cfu, colony-forming units. 
E. coli $\mathrm{O} 157$ or other pathogens has been performed mainly using food plants or their constituents such as tea catechins (Toda et al. 1989) and essential oils (Hammer et al. 1999). However, surveys of the shedding of E. coli $\mathrm{O} 157$ by cattle in the USA have shown negative associations between shedding and the feeding of clover and of cottonseed, leguminous plants that contain a particularly rich variety of secondary plant compounds (Rasmussen et al. 1999). A dietary regimen including periods in which sheep were fed sagebrush grass, which contains essential oils with antibacterial properties, has been shown to reduce the shedding of E. coli $\mathrm{O} 157$ by sheep (Kudva et al. 1995).

The present study confirmed that esculin and esculetin maintained their inhibitory activity towards a strain of E. coli $\mathrm{O} 157$ when tested in both human colon- and rumen-simulating fermenter systems over a period of weeks. There was no indication of adaptation of the test strain, E. coli O157 (12900), during this time. These data suggest that a dietary supplement of esculin might reduce the numbers of E. coli $\mathrm{O} 157$ in the animal gut. They further suggest that the effect may be specific to the E. coli serogroup $\mathrm{O} 157$ while the overall coliform numbers were unaffected, which suggests that the mode of action has some strain- or serotype-based specificity. Genome sequencing shows that E. coli O157 differs in its gene complement to other E. coli (Ohnishi et al. 1999); it would not therefore be surprising if these genetic differences altered the susceptibility of the bacteria to specific inhibitors. The human colon fermenter medium used here was relatively rich in fermentable carbohydrate, whereas the rumen fermenter was supplied with mineral salts and received periodic 'feeds' of a pelleted sheep ration. In the rumen fermenter studies, the addition of esculin to the fermenter resulted in an increase in the total numbers of viable anaerobes. Esculin hydrolysis releases glucose, providing a growth substrate for anaerobes and resulting in enhanced SCFA levels which may have contributed to the decreased survival of E. coli O157.

In calves, the effect of esculin did not reach statistical significance. The results are nonetheless encouraging, as E. coli was detected less frequently in the esculin-fed group. The use of the marked rifampicin-resistant $E$. coli O157 strain $\left(12900^{\mathrm{R}}\right)$ and antibiotic selection agar in the animal studies allowed the detection of low levels of the organism in faecal samples.

Given the scarcity of the facilities for experiments with animals and the complex ethical issues involved, the in vitro model systems used in the present study can provide conditions similar to those in the gut, particularly in relation to turnover time and $\mathrm{pH}$. They thus offer an alternative to batch incubations for the assessment of the possible effects of dietary additives on the survival of pathogens.

Recent observations on the distribution of E. coli $\mathrm{O} 157$ in cattle at slaughter suggest that the colon is an important habitat for this bacterium (Laven et al. 2003). For maximum protective effect, it may be necessary to ensure that compounds or treatments intended to inhibit the growth and survival of E. coli $\mathrm{O} 157$ reach the large bowel, perhaps by the use of timed-release encapsulation or other methods. More knowledge of the ecology of
E. coli $\mathrm{O} 157$ in the digestive tract will help to improve nutritional strategies to reduce the incidence of this pathogen in farm animals.

\section{Acknowledgements}

We thank Kenneth Young for technical assistance and Greitje Zuur (BIOSS) for statistical advice, DEFRA for support of C. McW. L. and BBSRC for support of K. N. S. The Rowett Research Institute is funded by the Scottish Executive Environment and Rural Affairs Department (SEERAD).

\section{References}

Barbosa TM \& Levy SB (2000) The impact of antibiotic use on antibiotic resistance development and persistence. Drug Resist Uptake 3, 303-311.

Bryant MP (1972) Commentary on the Hungate technique for culture of anaerobic bacteria. Am J Clin Nutr 25, 1324-1328.

Chapman PA \& Siddons CA (1996) A comparison of immunomagnetic separation and direct culture for the isolation of verocytotoxin-producing Escherichia coli $\mathrm{O} 157$ from cases of bloody diarrhoea, non-bloody diarrhoea and asymptomatic contacts. J Med Microbiol 44, 267-271.

Chesson A, Stewart CS \& Wallace RJ (1982) Influence of plant phenolic acids on growth and cellulolytic activity of rumen bacteria. Appl Environ Microbiol 44, 597-603.

Dean-Nystrom EA, Bosworth BT, Moon HW \& O'Brien AD (1998) Escherichia coli O157:H7 requires intimin for enteropathogenicity in calves. Infect Immun 66, 4560-4563.

Diez-Gonzalez F, Callaway TR, Kizoulis MG \& Russell JB (1998) Grain feeding and the dissemination of acid-resistant Escherichia coli from cattle. Science 281, 1666-1668.

Duncan SH (2001) Effects of rumen and gut microorganisms and their metabolites on the growth and survival of Escherichia coli $\mathrm{O} 157 . \mathrm{PhD}$ thesis, University of Aberdeen, Aberdeen, Scotland, UK.

Duncan SH, Flint HJ \& Stewart CS (1998) Inhibitory activity of gut bacteria against Escherichia coli $\mathrm{O} 157$ mediated by dietary plant metabolites. FEMS Microbiol Lett 164, 283-288.

Flint HJ, Duncan SH \& Stewart CS (1987) Transmissible antibiotic resistance in strains of Escherichia coli isolated from the ovine rumen. Lett Appl Microbiol 5, 47-49.

Franks AH, Harmsen HJM, Raangs GC, Jansen GJ, Schut F \& Welling GW (1998) Variations in bacterial populations in human faeces measured by fluorescent in situ hybridization with group-specific 16S rRNA targeted oligonucleotide probes. Appl Environ Microbiol 64, 3336-3345.

Griffin PM \& Tauxe RV (1991) The epidemiology of infections caused by Escherichia coli O157:H7, other enterohemorrhagic E. coli, and associated hemolytic uremic syndrome. Epidemiol Rev 13, 60-98.

Hammer KA, Carlson CF \& Riley TV (1999) Antimicrobial activity of essential oils and other plant extracts. J Appl Microbiol 86, 985-990.

Hungate RE (1966) The Rumen and its Microbes. New York: Academic Press.

James CE, Stanley KN, Allison HE, Flint HJ, Stewart CS, Sharp RJ, Saunders JR \& McCarthy AJ (2001) Lytic and lysogenic infection of diverse Escherichia coli and Shigella strains with a verocytotoxigenic bacteriophage. Appl Environ Microbiol 67, 4335-4337.

Kudva IT, Blanch K \& Hovde CJ (1998) Analysis of Escherichia coli $\mathrm{O} 157: \mathrm{H} 7$ survival in ovine or bovine manure and manure slurry. Appl Environ Microbiol 64, 1363-1370. 
Kudva IT, Hatfield PG \& Hovde CJ (1995) Effect of diet on the shedding of Escherichia coli O157 in a sheep model. Appl Environ Microbiol 61, 3166-3174.

Laven RA, Ashmore A \& Stewart CS (2003) Escherichia coli in the rumen and colon of slaughter cattle, with particular reference to $E$ coli $\mathrm{O} 157$. Vet $J \mathbf{1 6 5}, 78-83$.

McDougall EI (1948) Studies on ruminant saliva. 1. The composition and output of sheep's saliva. Biochem J 43, 99-109.

Macfarlane GT, Hay S \& Gibson GR (1989) Influence of mucin on glycosidase, protease and arylamidase activities of human gut bacteria grown in a 3 -stage continuous culture system. $J$ Appl Bacteriol 66, 407-417.

McKain N, Wallace RJ \& Watt ND (1992) Selective isolation of bacteria with dipeptidyl aminopeptidase type I activity from the sheep rumen. FEMS Microbiol Lett 95, 169-174.

Miyazaki K, Martin JC, Marinsek-Logar R \& Flint HJ (1997) Degradation and utilization of xylans by the rumen anaerobe Prevotella bryantii (formerly $P$ ruminicola subsp. brevis) $\mathrm{B}_{1} 4$. Anaerobe 3, 373-381.

Moniello G, Richardson AJ, Duncan SH \& Stewart CS (1996) Effects of coumarin and sparteine on attachment to cellulose and cellulolysis by Neocallimastix frontalis RE1. Appl Environ Microbiol 62, 4666-4668.

Murray RDH, Mendez J \& Brown SA (1982) The Natural Coumarins: Occurrence, Chemistry and Biochemistry. Chichester, UK: Wiley.

Nagy JG \& Tengerdy RP (1968) Antibacterial action of essential oils of Artemisia as an ecological factor. Appl Microbiol 16, 441-444.

Neill MA (1998) Treatment of disease due to shiga toxin-producing Escherichia coli: infectious disease management. In Escherichia coli O157:H7 and Other Shiga Toxin-producing E coli Strains, pp. 357-363 [JB Kaper and AD O'Brien, editors]. Washington DC: ASM.

Ohnishi M, Tanaka C, Kuharas S, et al. (1999) Chromosome of the enterohemorrhagic Escherichia coli O157:H7; comparative analysis with K-12 MG1655 revealed the acquisition of large amounts of foreign DNAs. DNA Res 6, 361-368.

Parry SM \& Salmon RL (1998) Sporadic STEC O157 infection: secondary household transmission in Wales. Emerg Infect Dis 4, 657-661.

Pryde SE, Duncan SH, Hold GL, Stewart CS \& Flint HJ (2002) The microbiology of butyrate formation in the human colon. FEMS Microbiol Lett 217, 133-139.

Ramsak A, Peterka M, Tajima K, Martin JC, Wood J, Johnston MEA, Aminov RI, Flint HJ \& Avgustin G (2000) Unravelling the genetic diversity of ruminal bacteria belonging to the CBF phylum. FEMS Microbiol Ecol 33, 69-79.

Rasmussen MA, Cray WC Jr, Casey TA \& Whipp SC (1993) Rumen contents as a reservoir of enterohemorrhagic Escherichia coli. FEMS Microbiol Lett 114, 79-84.

Rasmussen MA, Wickman TA, Cray WC Jr \& Casey TA (1999) Escherichia coli $\mathrm{O} 157$ and the rumen environment. In Escherichia coli O157 in Farm Animals, pp. 39-49 [CS Stewart and HJ Flint, editors]. Wallingford: CABI Publishing.

Richardson AJ, Calder AG, Stewart CS \& Smith A (1989)
Simultaneous determination of volatile and non-volatile acid fermentation products of anaerobes by capillary gas chromatography. Lett Appl Microbiol 9, 5-8.

Russell JB \& Rychlik JL (2001) Factors that alter rumen microbial ecology. Science 292, 1119-1122.

Sambrook J, Fritsch EF \& Maniatis T (1982) Molecular Cloning a Laboratory Manual, 2nd ed. Cold Spring Harbor, NY: Cold Spring Harbor Laboratory.

Scott KP, Mercer DK, Glover LA \& Flint HJ (1998) The green fluorescent protein as a visible marker for lactic acid bacteria in complex ecosystems. FEMS Microbiol Ecol 26, 219-230.

Shoemaker NB, Vlamakis H, Hayes K \& Salyers AA (2001) Evidence for extensive resistance gene transfer among Bacteroides spp. and among Bacteroides and other genera in the human colon. Appl Environ Microbiol 64, 1390-1399.

Suau A, Bonnet R, Sutren M, Godon J-J, Gibson GR, Collins MD \& Dore J (1999) Direct analysis of genes encoding 16S rRNA from complex communities reveals many novel molecular species within the human gut. Appl Environ Microbiol 65, $4799-4807$.

Tajima K, Aminov RI, Nagamine T, Ogata K, Nakamura M, Matsui H \& Benno Y (1999) Rumen bacterial diversity as determined by sequence analysis of $16 \mathrm{~S}$ rDNA libraries. FEMS Microbiol Ecol 29, 159-169.

Teather RM \& Sauer FD (1988) A naturally-compartmented rumen simulation system for the continuous culture of rumen bacteria and protozoa. J Dairy Sci 71, 666-673.

Toda M, Okubo S, Hiyoshi R \& Shimamura T (1989) The bactericidal activity of tea and coffee. Lett Appl Microbiol 8, $123-125$.

Van Soest PJ (1994) The Nutritional Ecology of the Ruminant, 2nd ed. Ithaca, NY: Cornell University Press.

Wallace RJ, Arthaud L \& Newbold CJ (1994) Influence of Yucca shidigera extract on rumen ammonia concentrations and ruminal microorganisms. Appl Environ Microbiol 60, $1762-1767$.

Wallace RJ, Falconer ML \& Bhargava PK (1989) Toxicity of volatile fatty acids at rumen pH prevents enrichment of Escherichia coli by sorbitol in rumen contents. Curr Microbiol 19, $277-281$.

Wilson KH (1997) Biota of the human gastrointestinal tract. In Gastrointestinal Microbiology, Vol. 2, pp. 39-58 [RI Mackie, BA Whyte and RE Isaacson, editors]. New York: ITP.

Wolin MJ (1969) Volatile fatty acids and inhibition of Escherichia coli growth by rumen fluid. Appl Environ Microbiol 17, 83-87.

Wolin MJ (1981) Fermentation in the rumen and the human large intestine. Science 213, 1463-1468.

Wong CS, Jelacic S, Habeeb RL, Watkins SL \& Tarr PI (2000) The risk of the hemolytic-uremic syndrome after antibiotic treatment of Escherichia coli O157:H7 infections. New Eng J Med 342, 1930-1936.

Zhao T, Doyle MP, Harmon BG, Brown CA, Mueller POE \& Parks AH (1998) Reduction of carriage of enterohaemorrhagic Escherichia coli $\mathrm{O} 157: \mathrm{H} 7$ in cattle by inoculation with probiotic bacteria. J Clin Microbiol 36, 641-647. 